
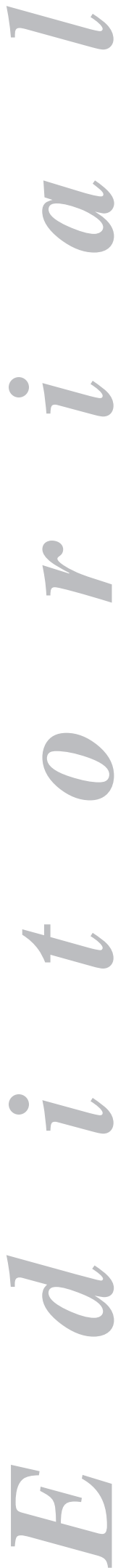

\section{A sonograph in the proctology clinic - an aid to the "learned finger"}

In this issue of the Spanish Journal of Gastroenterology, Dr. García-Montes et al. (1) pose an appealing question - should anorectal ultrasonography be included as a diagnostic tool for chronic anal pain? Following an interesting study their answer is yes, and they conclude that US is a valuable procedure. Pondering all this, we decided to assess this test among those available for proctological semiology.

While numerous studies are currently available to help in the diagnosis of anorectal disease, including rectosigmoidoscopy, manometry, ultrasonography and magnetic resonance imaging, there is no doubt that digital rectal exam has been and still remains the most valuable test in a coloproctologist's office. Very often, a rectal exam by experienced hands determines patient management and represents the grounds on which the best therapeutic option is decided upon (2). Adding ultrasonographic images of the sphincter area to this "learned finger" therefore represents an appealing alternative.

However, anal pain is the most common complaint in patients seen by proctologists, and the first question arising is whether a good anorectal sonogram can be obtained with an aching anus. The answer, as with digital rectal examination, is that gentleness should be used. On assessing initial patient rejection of rectal exams up to $59.4 \%$ of subjects consider the test acceptable beforehand whereas $91.5 \%$ consider it acceptable upon completion $(\mathrm{p}<0.001)$. Furthermore, perceived pain on a visual analog scale is 1.69 with a range of 0 to10 ( 0 is absent pain, 10 is maximum pain) in contrast to the widespread belief that this procedure is always painful, and over $96 \%$ of patients would recommend it to any friend in need of a rectal exam $(3,4)$. Moreover, in a personal series we found that all patients referred for anal pain accepted anorectal US once informed, which could be completed uneventfully in every instance (5). In view of these figures discomfort is not really a barrier to this exam.

From a skeptical standpoint we might claim that physical exploration with perianal visualization and a digital rectal exam usually suffices -in the hands of experienced clinicians- to reach an accurate diagnosis and initiate appropriate therapy in many patients with anal pain. Why then do we need an ultrasonograph in our office? Most common causes of pain include organic conditions such as fissure, hemorrhoidal thrombosis, and perianal abscess. These conditions are no doubt readily recognizable during routine examination, but anorectal US, when available, will provide highly relevant information such as whether fissures are associated with internal anal sphincter hypertrophy, the dimensions and precise location of thrombi, and the position and extension of perianal abscesses. No doubt these are key data when making therapeutic decisions such as performing a sphincterotomy or locating the best area for abscess drainage (6). 
At times physical exploration reveals no abnormalities and diagnosis requires further inquiry. Functional anorectal pain belongs in the functional gastrointestinal disorders category, namely among functional anorectal disorders together with incontinence and defecation changes (7). Its prevalence among the general population is estimated between 3 and $14 \%(8,9)$ according to the various series, and its diagnosis requires the exclusion of organic causes with physical, endoscopic, and radiographic exams. Patients consulting for this type of pain are few, less than $15 \%$ of cases, since attacks are self-limited and uncommon, with a frequency of around 1 per month (yearly mean of 13, range between 1 and 180) (8). Two types of functional anorectal pain exist: chronic proctalgia and proctalgia fugax. The former is characterized by diffuse, dull pain or high-pressure sensation in the rectum that usually worsens when sitting. Its prevalence is around $6.6 \%$ of the population, and seems somewhat more common in women and middle-agers (30-60 years). When pain can be reproduced by selective puborectal muscle palpation the condition is designated levator ani syndrome. When pain cannot be evoked by rectal exam maneuvers it is designated unspecified functional anorectal pain, which many authors relate to stress, tension, and anxiety (10). Proctalgia fugax consists of sudden, severe pain in the anus that may last from a few seconds to several minutes, and then completely subsides. Its prevalence is estimated between 8 and $18 \%$ of the population, with a similar distribution among genders. Symptoms within the previous 3 months are essential for either diagnosis, and other conditions should also be ruled out. A form of hereditary sphincter hypertrophy presents with both anal pain consistent with proctalgia fugax and constipation -hypertrophic myopathy of the internal anal sphincter (11). This diagnosis can only be appropriately suggested by measuring IAS thickness with ultrasounds. Diagnosis confirmation requires a biopsy demonstrating vacuolization in smooth muscle cells. This condition should be ruled out in patients with sphincter hypertrophy unresponsive to medical treatment since surgery with lateral internal sphincterotomy is required. Here endorectal ultrasounds are essential and provide an accurate measurement of sphincter rings.

Another highly relevant aspect in a proctology clinic is postoperative pain. In our experience (5) most patients consulting for long-term postoperative anal pain had undergone surgery for anal fissure. Clinical exploration revealed fissure persistence, and the most common finding on ultrasounds was incomplete sphincterotomy. This information suggests a definite treatment. On the other hand, when ultrasonography reveals subfissural cavities or abscesses following lateral internal sphincterotomy for anal fissure, even if surgery was successful their cleaning and coring out should be considered to relieve chronic postoperative pain.

A highly important aspect is that this examination should be performed by the one with a "learned finger". It has been demonstrated that the yield of anorectal ultrasounds significantly decreases when performed by radiologists rather than clinicians with expertise in anorectal disorders. Thus, for instance, in attempting to locate a fistula's internal orifice, the procedure was successful for $48-60 \%$ of fistulas when performed by a radiologist $(12,13)$. However, this figured reached over $95 \%$ when the procedure was carried out by an expert colorectal surgeon (6).

Exploration cost is no minor issue either. While this is a rapid exam using up few fungible goods, the current costs of equipments, most notably advanced 3D devices, makes it difficult to have a private ultrasonograph for our coloproctology clinics. Therefore we recommend shared-resources solutions based on multifunctional models. This is easy to advocate for if the diagnostic potential of rectoanal ultra- 
sounds for anal pain is added to that already shown for fecal incontinence, perianal fistula, and anorectal cancer staging (14).

To conclude, we may state that endoanal ultrasonography has a high diagnostic yield in patients with anal pain, and its related discomfort is comparable to that of digital rectal examination. Furthermore, its effectiveness and availability make it the first test to perform for patients with uncertain diagnosis, and an add-on aid in those with a definite one. In short, a "learned finger" with a sonograph at hand will establish further learned diagnoses and more effective therapeutic approaches for proctological patients.

\section{ACKNOWLEDGEMENTS}

We are grateful to our colleagues María del Carmen Martínez-Puente and José Antonio Pascual-Montero, Unidad de Coloproctología, Clínica Cemtro, Madrid, for their permanent contribution regarding proctological ultrasonography.

\section{García-Olmo ${ }^{1}$ and I. Pascual-Migueláñez ${ }^{2}$}

${ }^{I}$ Unit of Colorectal Surgery. La Paz University Hospital. Universidad Autónoma. Madrid, Spain. ${ }^{2}$ Unit of Coloproctology. Clínica Cemtro. Madrid, Spain. Department of General and Digestive Surgery. Hospital Infanta Sofía. Madrid, Spain

\section{REFERENCES}

1. García Montes MJ, Argüelles Arias F, Jiménez Contreras S, Sánchez Gey S, Pellicer Bautista F, Herrerías Gutiérrez JM. Should anorectal ultrasonography be included as a diagnostic tool for chronic anal pain? Rev Esp Enferm Dig 2010; 102(1): 7-14.

2. Talley NJ. How to do and interpret a rectal examination in gastroenterology. Am J Gastroenterol 2008; 103: $820-2$.

3. Furlan AB, Kato R, Vicentini F, Cury J, Antunes AA, Srougi M. Patient's reactions to digital rectal examination of the prostate. Int Braz J Urol 2008; 34(5): 572-5.

4. Romero FR, Romero AW, Brenny Filho T, Bark NM, Yamazaki DS, de Oliveira FC. Patients' perceptions of pain and discomfort during digital rectal exam for prostate cancer screening. Arch Esp Urol 2008; 61(7): 8504.

5. Pascual I, García Olmo D, Martínez Puente C, Pascual Montero JA. Ultrasound findings in spontaneous and postoperative anal pain. Rev Esp Enferm Dig 2008; 100: 764-7.

6. Pascual Migueláñez I, García-Olmo D, Martínez-Puente MC, Pascual Montero JA. Is routine endoanal ultrasound useful in anal fistulas? Rev Esp Enferm Dig 2005; 97(5): 323-7.

7. Bharucha AE, Wald A, Enck P, Rao S. Functional anorectal disorders. Gastroenterology 2006; 130: 1510-8.

8. de Parades V, Etienney I, Bauer P, Taouk M, Atienza P. Proctalgia fugax: demographic and clinical characteristics. What every doctor should know from a prospective study of 54 patients. Dis Colon Rectum 2007; 50(6): 893-8.

9. Wald A. Disorders of the anorectum, functional anorectal and pelvic pain. Gastroenterology Clinics 2001; 30: 243-351.

10. Whitehead WE, Wald A, Diamant NE, Enck P, Pemberton JH, Rao S. Functional disorders of the anus and rectum. Gut 1999; 45: 55-9.

11. Martorell P, Azpiroz F, Malagelada JR. Hypertrophic myopathy of the internal anal sphincter: a rarely recognized cause of proctalgia. Rev Esp Enferm Dig 2005; 97: 527-9.

12. Poen AC, Felt-Bersma RJ, Eijsbouts QA, Cuesta MA, Meuwissen SG. Hydrogen peroxide-enhanced transanal ultrasound in the assessment of fistula-in-ano. Dis Colon Rectum 1998; 41: 1147-52.

13. Ortiz H, Marzo J, Armendáriz P, Jiménez G. Valor de la ecografía endoanal con inyección de agua oxigenada en el diagnóstico de las fístulas perianales. Cir Esp 2002; 72: 315-7.

14. García Montes MJ, Caunedo Álvarez A, Herrerías Gutiérrez JM. Utility of the endo-rectal ultrasonography with sectorial transducer in the study of rectoanal pathology. Rev Esp Enferm Dig 2001; 93: 509-18. 